\title{
Use of the CytoSorb adsorption device in MDMA intoxication: a first-in-man application and in vitro study
}

\author{
Corinna N. Lang ${ }^{1,2^{*}}$, Michaela J. Sommer ${ }^{3}$, Merja A. Neukamm³, Dawid L. Staudacher ${ }^{1,2}$, Alexander Supady ${ }^{1,2}$, \\ Christoph Bode ${ }^{1,2}$, Daniel Duerschmied ${ }^{1,2}$ and Achim Lother ${ }^{1,2,4^{*}}$ (i)
}

\footnotetext{
* Correspondence: corinna.nadine. lang@universitaets-herzzentrum.de; achim.lother@universitaetsherzzentrum de

${ }^{1}$ Department of Cardiology and Angiology I, Faculty of Medicine, Heart Center Freiburg University, University of Freiburg, Hugstetter Str. 55, 79106 Freiburg, Germany Full list of author information is available at the end of the article
}

\begin{abstract}
Background: 3,4-Methylenedioxymethamphetamine (MDMA, "ecstasy") abuse is frequent, and overdosing might cause severe and eventually lethal multi-organ failure. To date, there is no causal therapy of MDMA intoxication and removal of MDMA from the circulation might be a reasonable measure to prevent adverse courses after overdosing. We present here first-in-man experience and in vitro data supporting a potential role of an adsorber device in severe MDMA overdosing.

Results: We applied a CytoSorb adsorber device in a 21-year-old male presenting with severe MDMA intoxication and multi-organ failure, including neurological impairment, hyperpyrexia, rhabdomyolysis, oliguric renal failure, liver failure, and coagulopathy with disseminated gastrointestinal and intramuscular bleeding. Use of the adsorber device was associated with a decline in MDMA concentrations in serum from 540 to $140 \mathrm{ng} / \mathrm{ml}$ within the first $24 \mathrm{~h}$, a decrease of interleukin 6 and myoglobin levels, and subsequent clinical improvement. The patient was discharged from hospital after restoration of organ function and full neurological recovery. Effective elimination of MDMA by the adsorber device could be confirmed in vitro, when the device lowered MDMA concentrations to non-detectable levels.

Conclusions: We report here first-in-man experience and in vitro data showing the capacity of a CytoSorb adsorber device for MDMA removal. Early integration of CytoSorb use may enhance the management of severe MDMA intoxication, though we cannot prove whether clinical improvement was directly related to elimination of MDMA or beneficial effects on rhabdomyolysis, hyperinflammation, or liver failure. Our findings encourage further investigation of the CytoSorb adsorber device in a prospective study and to evaluate its use for other intoxications.
\end{abstract}

Keywords: MDMA, Intoxication, Multi-organ failure, Adsorption (c) The Author(s). 2020 Open Access This article is licensed under a Creative Commons Attribution 4.0 International License, which permits use, sharing, adaptation, distribution and reproduction in any medium or format, as long as you give appropriate credit to the original author(s) and the source, provide a link to the Creative Commons licence, and indicate if changes were made. The images or other third party material in this article are included in the article's Creative Commons licence, unless indicated otherwise in a credit line to the material. If material is not included in the article's Creative Commons licence and your intended use is not permitted by statutory regulation or exceeds the permitted use, you will need to obtain permission directly from the copyright holder. To view a copy of this licence, visit http://creativecommons.org/licenses/by/4.0/. 


\section{Background}

3,4-Methylenedioxymethamphetamine (MDMA, "ecstasy") is among the top ten drugs leading to emergency presentations in the USA and Europe [1, 2]. Approximately $1.7 \%$ of the young adult population have used MDMA within the last 12 months [2]. Although the rate of adverse events is lower than in other drugs of abuse, courses of severe MDMA intoxication range from full recovery to fatal outcomes [3-8]. The risk of death from a single use of MDMA has been estimated up to 1:20,000 [1]. MDMA stimulates the release of serotonin, dopamine, and norepinephrine, leading to the desirable feelings of increased energy and euphoria. However, overdosing might cause coma, seizures, liver failure, and hyperthermia with rhabdomyolysis, renal failure, and disseminated intravascular coagulopathy, likely due to serotonin syndrome [1,9]. The current therapy of severe MDMA intoxication is non-causal and largely limited to sedation, cooling, and treatment of organ failure.

Removal of MDMA from the circulation might be an appropriate measure to prevent fatal adverse events after overdosing. The CytoSorb ${ }^{\circ}$ adsorption device (CytoSorbents Europe, Berlin, Germany) contains porous polymer beads that adsorb cytokines but also other molecules within the 5-55 kDa range, e.g., myoglobin, bilirubin, and several therapeutic drugs, in a concentration-dependent manner [10, 11]. The adsorber cartridge Cytosorb consists of polystyrene divinyl benzene copolymer beads with a biocompatible polyvinyl pyrrolidone polymer coating. The beads have a size of approximately $300-800 \mu \mathrm{m}$ with pores of approximately $20-50$ A. The adsorption device is increasingly used for different indications, including critically ill patients with sepsis or postresuscitation syndrome [12-14]. We describe here first-in-man experience and provide in vitro data supporting a potential use of a CytoSorb adsorber device in MDMA intoxication.

\section{Results}

\section{In-man application}

A 21-year-old, previously healthy male (height $178 \mathrm{~cm}$, body weight $56 \mathrm{~kg}$ ) was admitted to the emergency department after MDMA, clonazepam, and pregabalin abuse. $\mathrm{He}$ presented with typical symptoms of severe MDMA intoxication including neurological impairment (Glasgow coma scale 6), mydriasis, hyperpyrexia (body temperature $40.3^{\circ} \mathrm{C}$ ), tachycardia (heart rate $167 / \mathrm{min}$, blood pressure $98 / 61 \mathrm{mmHg}$ ), and dehydration. Shortly after arrival, he had tonic-clonic convulsive seizures requiring endotracheal intubation. Hypoglycemia was corrected and body temperature lowered to $39^{\circ} \mathrm{C}$ by cold infusions and a single dose of paracetamol. A computed tomography scan did not reveal any cerebral pathology.

After being transferred to the intensive care unit, he showed recurrent hyperthermia and rapidly developed massive rhabdomyolysis (myoglobin 75,420 ng/ml), oliguric renal (serum creatinine $3.54 \mathrm{mg} / \mathrm{dl}$ ) and liver failure (MELD score 36, Fig. 1a) [15], and severe coagulopathy with disseminated gastrointestinal and intramuscular bleeding. During the first $15 \mathrm{~h}$, plasmatic coagulation and fibrinogen levels decreased beyond the detectable range. Hemoglobin and platelet counts dropped by $70 \%$ ( $\mathrm{Hb} 16.1$ to $4.9 \mathrm{~g} / \mathrm{dl}$ ) and 73\% (platelets 196 to 52 cells/nl), respectively. Transfusion of 3 red blood cell concentrates, 3 platelet concentrates, and 6 units of fresh frozen plasma; substitution of 

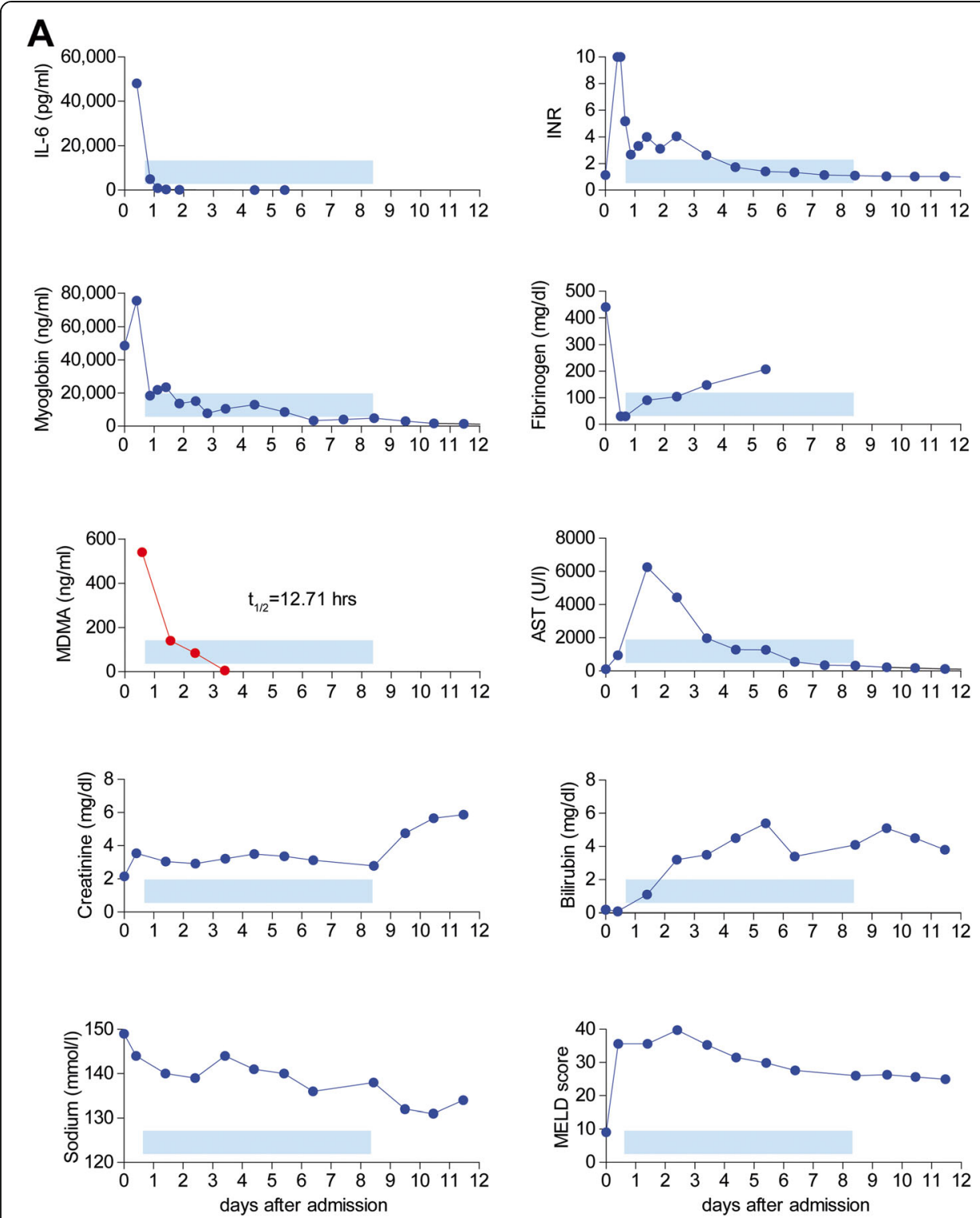

B

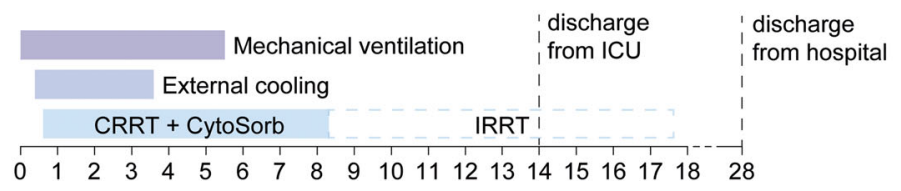

Fig. 1 Time course of laboratory findings and treatment milestones during clinical application of the adsorber device after MDMA intoxication. Serum concentrations of interleukin 6 (IL-6), myoglobin, 3,4methylenedioxymethamphetamine (MDMA), creatinine, sodium, bilirubin, and international normalized ratio (INR), fibrinogen levels, and aspartate amino transferase (AST) activity were repeatedly measured during the clinical course. MELD score (Model of End-Stage Liver Disease) was calculated to assess liver injury (a). Timeline indicating durations of mechanical ventilation (purple), external cooling (mid-blue), continuous renal replacement therapy (CRRT) with CytoSorb (light-blue), and intermittent renal replacement therapy (IRRT, dashed light-blue) (b) 
coagulation factors; and moderate vasopressor support were provided. Serum lactate increased to $4.3 \mathrm{mmol} / \mathrm{l}$ while fluid resuscitation using balanced crystalloid solution and albumin infusions was continued. Body temperature was maintained between 35.9 and $36.5^{\circ} \mathrm{C}$ by a surface cooling device (ArticSun ${ }^{\circ}$, Medivance, Louisville, CO, USA). Twenty-four hours after hospitalization, calculated SAPS II score of 85 predicted an inhospital mortality $95 \%$ [16].

First quantitative measurement of MDMA in blood serum $15 \mathrm{~h}$ after admission revealed a concentration of $540 \mathrm{ng} / \mathrm{ml}$, confirming the suspected severe overdosing and suggesting an even higher peak concentration. Clonazepam $(180 \mathrm{ng} / \mathrm{ml})$ and pregabalin $(660 \mathrm{ng} / \mathrm{ml})$ probably contributed little to the symptoms. For anuric renal failure, we initiated continuous renal replacement therapy (Fresenius Medical Care, multifiltrate Ci-Ca CVVHD, Ultraflux AV 1000S, blood flow $80 \mathrm{ml} / \mathrm{min}$, dialysate flow $1600 \mathrm{ml} / \mathrm{h}$, mean effluent flow rate $30.1 \mathrm{ml} / \mathrm{kg} / \mathrm{h}$ ) starting $16 \mathrm{~h}$ after admission and included a CytoSorb adsorption device into the hemodialysis circuit to treat rhabdomyolysis and systemic inflammation. During the first adsorption interval of $24 \mathrm{~h}$, myoglobin and interleukin-6 levels in serum quickly decreased by 76\% (myoglobin 75,420 to 18,400 ng/ $\mathrm{ml}$ ) and 90\% (IL-6 48,129 to $4991 \mathrm{pg} / \mu \mathrm{l}$ ), respectively (Fig. 1a). Adsorption therapy was continued for 7 days at constant blood flow of $80 \mathrm{ml} / \mathrm{min}$ with replacement of the device every $24 \mathrm{~h}$ ( 7 devices in total).

Though CytoSorb therapy was primarily initiated to treat rhabdomyolysis and systemic inflammation, we hypothesized that potential elimination of MDMA by the CytoSorb may have added further benefit to the patient. Serial measurements revealed a decline in MDMA concentrations in serum from 540 to $140 \mathrm{ng} / \mathrm{ml}$ within the first $24 \mathrm{~h}$ after adsorption therapy was started. During 3 days, serum MDMA levels of the patient showed a one-phase exponential decay with a calculated half-life of $12.71 \mathrm{~h}\left(R^{2}=0.990\right)$ despite persisting anuric renal failure (Fig. 1a). Within 36 to $48 \mathrm{~h}$ after admission, the patient's condition improved significantly. Serum lactate normalized and vasopressor support could be discontinued. Increasing fibrinogen levels and decreasing aspartate transaminase activity in serum suggested overcome coagulopathy and recovery of liver function. External cooling and mechanical ventilation could be discontinued at day 4 and 6 after admission, respectively, and the patient left the intensive care unit at day 14. Renal dysfunction fully resolved after 17 days of renal replacement therapy (Fig. 1b). Increasing fibrinogen levels and decreasing aspartate transaminase activity in serum suggested recovery of liver function (Fig. 1a). MELD score continuously improved to 9 at day 27. The patient showed full neurological recovery and was discharged to rehabilitation therapy at day 28 (Fig. 1b).

\section{Elimination of MDMA using the CytoSorb in vitro}

Following our clinical findings, we evaluated the capacity of the CytoSorb adsorber to eliminate MDMA in vitro. MDMA was dissolved in FCS at a similar concentration that was observed in our patient and circulated in a custom-made system including a CytoSorb adsorber device. After 5 min, MDMA concentration measured distal of the adsorber device was non-detectable, indicating full removal of MDMA by the adsorber. Serial measurements showed a one-phase exponential decay of MDMA in the reservoir with a calculated half-life of $8.32 \mathrm{~min}\left(R^{2}=0.993\right)$ (Fig. 2). 

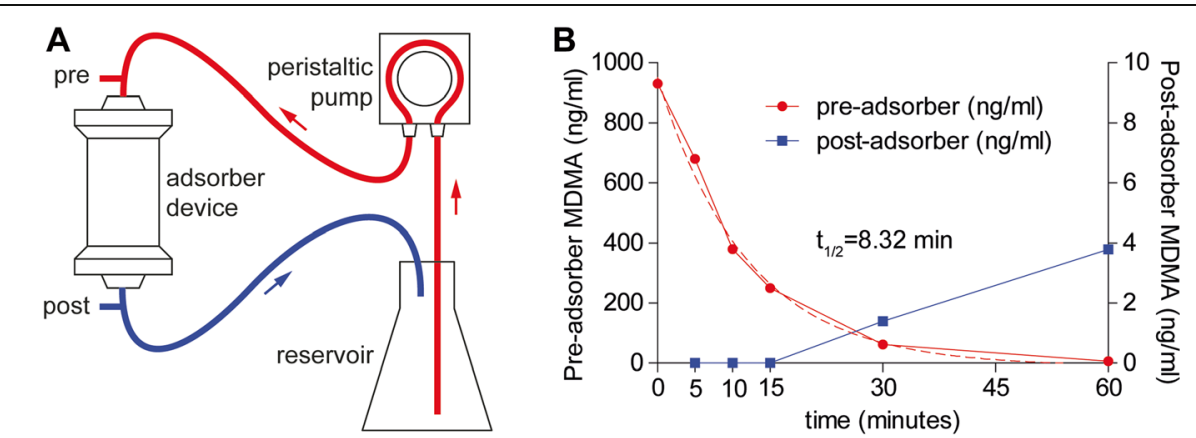

Fig. 2 Adsorption of MDMA in vitro. Serum containing 3,4-methylenedioxymethamphetamine (MDMA-FCS, $1 \mathrm{\mu g} / \mathrm{ml}$ ) was circulated from a reservoir at a flow rate of $170 \mathrm{ml} / \mathrm{min}$ (a). MDMA-FCS samples were taken from the circuit before (pre, red) and after (post, blue) the adsorber device at 0, 5, 10, 15, 30, and 60 min, and MDMA was quantified by HPLC (b). Dashed line indicates calculated half-life

Interestingly, after 30 and $60 \mathrm{~min}$, we detected a slight increase in post-adsorber MDMA concentration (1.4 and $3.8 \mathrm{ng} / \mathrm{ml}$ ) (Fig. 2).

\section{Discussion}

We report here first-in-man experience and in vitro data showing the capacity of a CytoSorb adsorber device for MDMA removal both in a clinical scenario and in vitro. Our data suggest that CytoSorb use may be beneficial in patients with severe MDMA intoxication.

MDMA content of "street" ecstasy is highly variable and has been increased during the past decade, thus aggravating the risk for intoxication [1, 2]. The CytoSorb device contains adsorber beads that are specifically designed to remove molecules between 4 and $20 \mathrm{kD}$ [17] but bind to a wide range of molecules. In this case, CytoSorb use was associated with a quick decrease in interleukin 6 and myoglobin levels, supporting the previously described beneficial effects of CytoSorb use on rhabdomyolysis, hyperinflammation, and liver failure [14]. Thus, CytoSorb use may be beneficial to attenuate organ damage secondary to MDMA intoxication. In addition, it has been shown that the CytoSorb device has a high binding capacity of substances of low molecular weight comparable to MDMA (193.2 D) including several therapeutic drugs, e.g., valproic acid, theophylline, and phenobarbital [11]. Due to a low volume of distribution of 4 to $71 / \mathrm{kg}$ [18] and protein binding of only $34-40 \%$ [19], there is a relevant proportion of free MDMA in blood. Additionally, the partially protonated basic nitrogen of MDMA (pKa 8.7) [20] may interact with the carboxylic acid amide of the pyrrolidone-coated surface of the beads. Therefore, an adsorption of MDMA on CytoSorb and subsequent removal seemed to be likely, but remained hard to predict. We show here that MDMA was effectively eliminated by the CytoSorb in vitro and its use may thus be promising after overdosing.

Other strategies for clearing inflammatory mediators in sepsis are undergoing clinical evaluation, including high-volume hemofiltration, cascade hemofiltration, plasmapheresis, or high cutoff hemofiltration, and may represent an alternative to CytoSorb [21, 22]. For example, it has been demonstrated that CRRT with a high cutoff hemofilter likewise facilitates interleukin 6 and myoglobin plasma clearance [23]. Whether this also applies to MDMA removal remains to be investigated. 
Importantly, time course and severity of the undesired pharmacological effects of MDMA largely follow blood concentration course although the correlation of the effects with the absolute MDMA concentration is rather low, especially in multiple dosing [24]. After intake, gastro-intestinal absorption of MDMA is rapid and peak plasma concentrations are attained after approximately $2 \mathrm{~h}$, which makes gastric lavage or charcoal use ineffective in most cases [1,9]. This implies that adsorber therapy should be initiated as early as possible in suspected severe overdosing to remove as much of the compound as possible and potentially prevent organ damage.

Plasma half-life of MDMA in the patient described here was $12.7 \mathrm{~h}$. In previous studies, mean plasma half-life of MDMA in healthy adults after controlled administration of a defined dose was 7-9 h $[9,18]$. However, pharmacokinetics of MDMA is nonlinear, and elimination is prolonged at higher concentrations due to saturation or inhibition of metabolizing enzymes. This effect was already evident at concentrations ranging from 163 to $292 \mathrm{ng} / \mathrm{ml}$, but MDMA peak concentration in our case was at least $540 \mathrm{ng} / \mathrm{ml}[9,18]$. Data on the metabolism and renal clearance of MDMA in patients with liver and kidney failure, which was present in our patient, is not available, but the organ failure probably further impairs drug elimination and prolongs plasma half-life. Interestingly, in vitro, the post-adsorber MDMA concentration slightly increased after $30 \mathrm{~min}$. The capacity of the adsorber depends on the amount of available sorbent, suggesting a beginning saturation of the adsorber device. Our finding is in line with previous studies when desorption of therapeutic drugs had been observed between 30 and 60 min of perfusion [11]. Importantly, this argues for an only moderate affinity of the adsorber to different drugs [11]. From a translational point of view, this finding suggests that frequent replacement of the adsorber device during clinical application could enhance efficacy and prevent desorption, but optimal replacement intervals remain to be investigated.

\section{Conclusions}

In conclusion, integration of CytoSorb use may enhance the management of severe MDMA intoxication. Though our data suggest that the use of an adsorber device facilitates the elimination of MDMA, we cannot prove whether this was directly related to clinical improvement. However, when initiated early, MDMA removal may add on the beneficial effects of CytoSorb use on rhabdomyolysis, hyperinflammation, and liver failure. Further investigations are necessary to validate our observations in a prospective study and to prove a causal relationship between the use of an adsorber device and clinical outcome. In addition, our findings encourage systematic testing of CytoSorb use for other intoxications.

\section{Methods}

\section{Patient selection and data acquisition}

We retrospectively evaluated the application of a CytoSorb adsorber device in a case of severe MDMA intoxication. Data were extracted from medical records. Written informed consent was obtained from the patient for publication of this report. Statistical analysis was performed using GraphPad Prism 5.04. 


\section{In vitro study}

To directly evaluate the capacity of the CytoSorb hemoadsorption device (CytoSorbents Europe, Berlin, Germany) to eliminate MDMA, we modified a previously published protocol [11]. A CytoSorb device was integrated in a custom-made system applying a peristaltic pump (AlphaControl PSP-V12G, Fig. 2). MDMA (Sigma-Aldrich, Taufkirchen, Germany) was dissolved at a concentration of $1 \mu \mathrm{g} / \mathrm{ml}$ in $2.500 \mathrm{ml}$ fetal calf serum (FCS, Sigma-Aldrich, Taufkirchen, Germany). The solution was circulated from a reservoir at a flow rate of $170 \mathrm{ml} / \mathrm{min}$ for $60 \mathrm{~min}$. Samples $(1 \mathrm{ml})$ were taken from the circuit simultaneously before (pre) and after (post) the adsorber device at $0,5,10,15$, 30, and $60 \mathrm{~min}$. MDMA concentrations were analyzed by a validated liquid chromatography-tandem mass spectrometry method after solid-phase extraction (lower limit of detection $0.6 \mathrm{ng} / \mathrm{ml}$, lower limit of quantification $0.8 \mathrm{ng} / \mathrm{ml}$ ). MDMA half-life was calculated by a one-phase exponential decay model $(Y=(\mathrm{YO}-\mathrm{NS}) \times \exp (-\mathrm{K} \times \mathrm{X})+$ NS) using GraphPad Prism 5.04.

\section{Abbreviations}

FCS: Fetal calf serum; MDMA: 3,4-Methylenedioxymethamphetamine

\section{Acknowledgements}

A. Lother is funded by the Berta-Ottenstein-Programme for Advanced Clinician Scientists, Faculty of Medicine, University of Freiburg. We thank the Institute of Clinical Chemistry and Laboratory Medicine, Medical Center, University of Freiburg, for excellent technical support and Bela Szabo, Institute of Experimental and Clinical Pharmacology and Toxicology, University of Freiburg, for his valuable input.

\section{Authors' contributions}

All authors contributed to the study conception and design. Material preparation, data collection, and analysis were performed by Corinna N. Lang, Michaela J. Sommer, Merja A. Neukamm, and Achim Lother. The first draft of the manuscript was written by Corinna N. Lang and Achim Lother, and all authors commented on previous versions of the manuscript. All authors read and approved the final manuscript.

\section{Funding}

This research did not receive any specific grant from funding agencies in the public, commercial, or not-for-profit sectors.

\section{Availability of data and materials \\ Not applicable}

\section{Ethics approval and consent to participate}

No ethics approval was required in this case.

\section{Consent for publication}

Written informed consent was obtained from the patient for publication of this report including clinical data and any accompanying images.

\section{Competing interests}

Corinna N. Lang, Alexander Supady and Daniel Duerschmied received speaker honoraria from CytoSorbents Europe. Daniel Duerschmied received a research grant from CytoSorbents Europe. All other authors have no conflict of interest or competing interest to declare.

\section{Author details}

${ }^{1}$ Department of Cardiology and Angiology I, Faculty of Medicine, Heart Center Freiburg University, University of Freiburg, Hugstetter Str. 55, 79106 Freiburg, Germany. ${ }^{2}$ Department of Medicine III (Interdisciplinary Medical Intensive Care), Medical Center, Faculty of Medicine, University of Freiburg, Freiburg, Germany. ${ }^{3}$ Institute of Forensic Medicine, Medical Center, Faculty of Medicine, University of Freiburg, Freiburg, Germany. ${ }^{4}$ Institute of Experimental and Clinical Pharmacology and Toxicology, Faculty of Medicine, University of Freiburg, Freiburg, Germany.

Received: 20 April 2020 Accepted: 31 May 2020

Published online: 15 June 2020

\section{References}

1. White CM (2014) How MDMA's pharmacology and pharmacokinetics drive desired effects and harms. J Clin Pharmacol 54:245-252

2. European Monitoring Centre for Drugs and Drug Addiction (2019) European Drug Report 2019: Trends and Developments. 
3. Vakde T, Diaz M, Uday K, Duncalf R (2014) Rapidly reversible multiorgan failure after ingestion of "Molly" (pure 3,4methylenedioxymethamphetamine): a case report. J Med Case Rep 8:204

4. Jahns FP, Pineau Mitchell A, Auzinger G (2018) Too hot to handle: a case report of extreme pyrexia after MDMA ingestion. Ther Hypothermia Temperature Manage 8:173-175

5. Shelton CP, Rosini JM (2015) Multisystem organ failure and death resulting from ingestion of "Molly" (3,4methylenedioxymethamphetamine). J Emerg Nurs 41:447-450

6. Davies O, Batajoo-Shrestha B, Sosa-Popoteur J, Olibrice M (2014) Full recovery after severe serotonin syndrome, severe rhabdomyolysis, multi-organ failure and disseminated intravascular coagulopathy from MDMA. Heart Lung 43:117-119

7. Connolly E, O'Callaghan G (1999) MDMA toxicity presenting with severe hyperpyrexia: a case report. Crit Care Resusc 1: 368-370

8. Armenian P, Mamantov TM, Tsutaoka BT, Gerona RR, Silman EF, Wu AH, Olson KR (2013) Multiple MDMA (Ecstasy) overdoses at a rave event: a case series. J Intensive Care Med 28:252-258

9. de la Torre R, Farre M, Roset PN, Pizarro N, Abanades S, Segura M, Segura J, Cami J (2004) Human pharmacology of MDMA: pharmacokinetics, metabolism, and disposition. Ther Drug Monit 26:137-144

10. Kellum JA, Song M, Venkataraman R (2004) Hemoadsorption removes tumor necrosis factor, interleukin-6, and interleukin-10, reduces nuclear factor-kappaB DNA binding, and improves short-term survival in lethal endotoxemia. Crit Care Med 32:801-805

11. Reiter K, Bordoni V, Dall'Olio G, Ricatti MG, Soli M, Ruperti S, Soffiati G, Galloni E, D'Intini V, Bellomo R, Ronco C (2002) In vitro removal of therapeutic drugs with a novel adsorbent system. Blood Purification 20:380-388

12. Lother A, Benk C, Staudacher DL, Supady A, Bode C, Wengenmayer T, Duerschmied D (2019) Cytokine adsorption in critically ill patients requiring ECMO support. Front Cardiovasc Med 6:71

13. Ankawi G, Xie Y, Yang B, Xie P, Ronco C (2019) What have we learned about the use of cytosorb adsorption columns? Blood Purif 48:196-202

14. Poli EC, Rimmele T, Schneider AG (2019) Hemoadsorption with CytoSorb((R)). Intensive Care Med 45:236-239

15. Kamath PS, Wiesner RH, Malinchoc M, Kremers W, Therneau TM, Kosberg CL, D'Amico G, Dickson ER, Kim WR (2001) A model to predict survival in patients with end-stage liver disease. Hepatology 33:464-470

16. Le Gall JR, Lemeshow S, Saulnier F (1993) A new Simplified Acute Physiology Score (SAPS II) based on a European/ North American multicenter study. JAMA 270:2957-2963

17. Kellum JA, Fink MP (2014) U.S. Patent No. 8,647,666 B2. U.S. Patent and Trademark Office, Washington, DC

18. Kolbrich EA, Goodwin RS, Gorelick DA, Hayes RJ, Stein EA, Huestis MA (2008) Plasma pharmacokinetics of 3,4methylenedioxymethamphetamine after controlled oral administration to young adults. Ther Drug Monit 30:320-332

19. Garrett ER, Seyda K, Marroum P (1991) High performance liquid chromatographic assays of the illicit designer drug "Ecstasy", a modified amphetamine, with applications to stability, partitioning and plasma protein binding. Acta Pharmaceutica Nordica 3:9-14

20. Baselt RC (2017) Disposition of toxic drugs and chemicals in man. Biomedical Pubns.

21. Honore PM, Jacobs R, Joannes-Boyau O, De Regt J, De Waele E, van Gorp V, Boer W, Verfaillie L, Spapen HD (2013) Newly designed CRRT membranes for sepsis and SIRS--a pragmatic approach for bedside intensivists summarizing the more recent advances: a systematic structured review. ASAIO J 59:99-106

22. Rimmele T, Kellum JA (2011) Clinical review: blood purification for sepsis. Crit Care 15:205

23. Weidhase L, Haussig E, Haussig S, Kaiser T, de Fallois J, Petros S (2019) Middle molecule clearance with high cut-off dialyzer versus high-flux dialyzer using continuous veno-venous hemodialysis with regional citrate anticoagulation: a prospective randomized controlled trial. PloS One 14:e0215823

24. Farre M, Tomillero A, Perez-Mana C, Yubero S, Papaseit E, Roset PN, Pujadas M, Torrens M, Cami J, de la Torre R (2015) Human pharmacology of 3,4-methylenedioxymethamphetamine (MDMA, ecstasy) after repeated doses taken $4 \mathrm{~h}$ apart Human pharmacology of MDMA after repeated doses taken 4 h apart. Eur Neuropsychopharmacol 25:1637-1649

\section{Publisher's Note}

Springer Nature remains neutral with regard to jurisdictional claims in published maps and institutional affiliations.

\section{Submit your manuscript to a SpringerOpen ${ }^{\circ}$ journal and benefit from:}

- Convenient online submission

- Rigorous peer review

- Open access: articles freely available online

High visibility within the field

- Retaining the copyright to your article

Submit your next manuscript at $\boldsymbol{\nabla}$ springeropen.com 